\title{
LA LEGITIMIDAD DEMOCRÁTICA DE LA RESTRICCIÓN DE DERECHO FUNDAMENTAL EN LA TEORÍA DEL CONSENSO DE JÜRGEN HABERMAS*
}

\author{
DEMOCRATIC LEGITIMACY OF THE RESTRICTION OF THE FUNDAMENTAL \\ RIGHT IN THE THEORY OF THE CONSENSUS OF JÜRGEN HABERMAS \\ LÉGITIMITÉ DÉMOCRATIQUE DE LA RESTRICTION DU DROIT \\ FONDAMENTAL DANS LA THÉORIE DU CONSENSUS DE JÜRGEN HABERMAS
}

Edimar Carmo da Silva**

\begin{abstract}
RESUMEN
Los derechos humanos, según la literatura autorizada, contienen un papel central en tribunales internacionales y especializados. La dimensión fundamental de estos derechos se proyecta en el orden interno de cada pais por medio de las Constituciones. En el Estado democrático de Derecho, los derechos fundamentales son formados por las fuerzas politicas y democráticas. Asimismo, para la restricción de estos derechos, en el proceso penal, es esencial la participación del interesado en la formación de la decisión del Tribunal. La democracia requiere la participación de la persona interesada en la elaboración de las decisiones de Estado. Esta comprensión se proyecta en la jurisdicción para adaptarla a la democracia y superar la "jurisdição-soberania", de los Estados autoritarios, para lograr la "jurisdição-participação", de los Estados democráticos. Según la teoría de Habermas, el discurso entre los participantes busca el consenso. Además, asegura que la restricción de derechos fundamentales ocurra con la participación de los interesados, rechazando cualquier decisión autoritaria.
\end{abstract}

Palabras Clave: Derechos Humanos - Derechos Fundamentales - Estado Democrático Consenso

ABSTRACT

Human rights, according to the authoritative literature, contain a central role in international and specialized Courts. The fundamental dimension of these rights is projected in the internal order of each country through the constitutions. In the democratic rule of law, fundamental rights are formed by political and democratic forces. Also, for the restriction of these rights in the criminal process, the participation of the interested party in the formation of the decision of the Court is essential. Democracy requires the participation of the person concerned in the elaboration of decisions of State. This understanding is projected in the jurisdiction to adapt to democracy and overcome the "jurisdição-soberania", authoritarian States, to achieve the "jurisdição-participação", of the democratic States. According to the theory of Habermas, discourse among participants seeks consensus. In addition, it ensures that the restriction of fundamental rights occur with the participation of interested parties, rejecting any authoritarian decision.

\footnotetext{
* Artículo recibido el 16 de abril de 2015 y aceptado para su publicación el 30 de junio de 2015.

** Abogado. Alumno regular en el curso para doctorado, en Derecho Constitucional, de la Universidad de Buenos Aires-UBA (ARG). Maestría en Ciencias Criminales - PUC/RS (BRA). Promotor de Justicia del Ministerio Público del Distrito Federal y Territorios (BRA). Profesor invitado de Posgrado del Centro Universitario Estácio/ Facitec-DF (BRA). Correspondencia a: Correo electrónico ecdse@hotmail.com.
} 
KEYWORDS: Human Rights - Fundamental right - Democratic State - Consensus

RÉSUMÉ

Droits de l'homme, selon la littérature faisant autoritaire, contiennent un rôle central dans les tribunaux internationaux et spécialisés. La dimension fondamentale de ces droits est prévue dans l'ordre interne de chaque pays à travers les constitutions. Dans l'état de droit démocratique, les droits fondamentaux sont formés par des forces politiques et démocratiques. En outre, la restriction de ces droits dans la procédure pénale, la participation de l'intéressé à la formation de la décision de la Cour est essentielle. La démocratie exige la participation de la personne concernée dans l'élaboration des décisions de l'État. Cette compréhension est projetée dans la compétence voulue pour s'adapter à la démocratie et de surmonter la «jurisdição-soberania», les États autoritaires, pour atteindre le "jurisdiçãa-participação», des Etats démocratiques. Selon la théorie d'Habermas, discours parmi les participants à la recherche d'un consensus. Assure, en outre, à la restriction des droits fondamentaux se produisent avec la participation des parties intéressées, rejetant toute décision autoritaire.

MotS CLÉs: Droits de l'Homme - Fondamentaux - État Démocratique - Consensus

\section{INTRODUCCIÓN}

El presente artículo tiene por finalidad analizar, en breves consideraciones, la legitimidad de la restricción de los derechos fundamentales a la luz de la teoría del consenso de Jürgen Habermas en el Estado democrático de derecho.

Es conveniente aclarar que el sentido de la palabra restricción de derechos fundamentales, diferente del significado de violación de derecho, dice relación respecto a la acción estatal que, obedeciendo las normas del debido proceso, legal y constitucional, en la persecución penal, tenga como consecuencia la mitigación del goce de algunos bienes fundamentales de la persona, tales como el patrimonio, la libertad, etcétera. Por su parte, la violación consiste en el acto de agresión producido contra la persona, sea por lo Estado o por particulares, en inobservancia de la cláusula del debido proceso.

Inicialmente será abordada la posición actual de los derechos humanos, así considerados, no sólo en la óptica internacional, sino también en el orden jurídico interno de un plan inspirado y guiado bajo el Estado democrático de derecho.

Se realizarán algunas observaciones sobre el Estado democrático de derecho, destacando sus aspectos distintivos en lo referente a un Estado de derecho, guiado por las reglas antidemocráticas. También se tendrá en cuenta la posible convergencia entre las normas democráticas la teoría del consenso concebida por Jürgen Habermas.

Finalmente, se hará un planteamiento sobre la legitimidad de la restricción de los derechos fundamentales de la persona a la luz de la teoría del consenso en el Estado democrático de derecho. En este sentido, conviene distinguir entre las decisiones estatales adoptadas por consenso de los sujetos afectados con decisiones autoritarias, en el que la jurisdicción actúa de oficio, es decir, sin la participación de las personas contra quien es solicitada la restricción de un derecho fundamental, como ocurre en la persecución penal. 


\section{LA DIMENSIÓN ACTUAL DE LOS DERECHOS HUMANOS Y FUNDAMENTALES}

Sin pretender profundizar sobre el origen, la evolución histórica y lo que son, en la cultura occidental, los derechos humanos, parece conveniente señalar la comprensión actual del contenido de los derechos fundamentales básicos de las personas.

El concepto de los derechos humanos puede extraerse de la breve lección de SiECKMANN en el siguiente sentido: "los derechos humanos se definen como derechos que rigen para todo ser humano por la sola condición de ser humano" ${ }^{1}$. Sin embargo, después de enfrentar los problemas de la mera condición humana para justificar tales derechos, así como la calificación de ciertos grupos específicos de personas, el mismo SiECKMANn concibe los derechos humanos a través de su validez. Así, son derechos humanos "los derechos de los seres humanos, que rigen y se deben observar en todos los sistemas jurídicos, independientemente de la normativa en el derecho positivo"2.

Aunque se hace referencia a los derechos humanos y las condiciones de los derechos fundamentales como expresiones sinónimas, cierta doctrina hace la distinción apropiada entre derechos humanos y los derechos fundamentales. En este sentido, como anota SARLET, los derechos humanos se refieren a los derechos contemplados en los documentos internacionales, mientras que los derechos fundamentales son los "direitos do ser humano reconhecidos e positivados na esfera do direito constitucional positivo"3.

Según la doctrina autorizada, las primeras fuentes históricas de los derechos humanos se derivan de la segunda mitad del siglo XVIII, precisamente: de la Constitución de Virginia de 1776 y de la declaración francesa de derechos humanos de $1789^{4}$. Sin embargo, esta concepción de los derechos humanos se deriva de la invocación de la ley natural, pero cuya existencia depende del derecho positivo.

PiOvesAn, al abordar la protección de los derechos humanos en el orden internacional, afirma que si la Segunda Guerra Mundial significó una ruptura con los derechos humanos, el periodo de posguerra debería significar su reconstrucción. Según la célebre autora, en el período pos Grande Guerra "Fortalece-se a idéia de

${ }^{1}$ Sieckmann, Jan (2012). "Derechos Humanos y Autonomía”. En: Internalización del Derecho Constitucional, Constitucionalización del Derecho Internacional, Buenos Aires: Editorial Eudeba/ Alexander von Humboldt, 1a Edición, p. 633.

2 Ídem.

${ }^{3}$ Sarlet, Ingo Wolfgang (2006). A Eficácia dos Direitos Fundamentais. Porto Alegre: Livraria do Advogado, 6a Edição, pp. 35-36. Traducción del autor: "los derechos humanos reconocidos en el ámbito del derecho constitucional positivo".

${ }^{4}$ Bulygin, Eugenio (1987). "Sobre el Status Ontológico de los Derechos Humanos". En: Doxa. Cuadernos de Filosofía del Derecho, No 4, p. 79. 
que a proteção dos direitos humanos não deve se reduzir ao domínio reservado ao Estado, porque revela tema de legítimo interesse internacional"5.

Desde otro punto, bajo la óptica interna del Estado, fue en el periodo post los regímenes autoritarios de los años veinte y treinta del siglo XX, en el que el mundo fue testigo de la abolición de los derechos constitucionales y garantías. Consonante con lo anterior, BuLYGIN ${ }^{6}$ sostiene que fue necesario proporcionar una fundamentación más consistente de los derechos humanos, además de la ley positiva, encaminadas a una mayor protección de estos derechos contra los regímenes autoritarios. Cierto es que el propio BuLYGIN admite una dificultad en reconocer lo que es este razonamiento a los derechos humanos propiamente dichos, ya sea desde la perspectiva de la ley natural, ya sea bajo la concepción positivista.

Sin embargo, Bulygin culmina en el reconocimiento de la necesidad de conferir un valor máximo de los derechos establecidos en sede constitucional. En este sentido, el célebre profesor de la Universidad de Buenos Aires concluye así: "si se quiere que los derechos humanos tengan vigencia efectiva hay que lograr que el legislador positivo los asegure a través de las disposiciones constitucionales correspondientes y que los hombres respeten efectivamente la constitución"7.

De hecho, la mayor manifestación de la efectividad de los derechos de las personas, especialmente los derechos fundamentales contemplados en un determinado Estado organizado políticamente, puede ser conferida a partir del grado de respeto de los derechos previstos en la Constitución. Desde el respeto por las normas constitucionales estableciendo derechos fundamentales es posible concebir una dimensión normativa superior, es decir, los derechos humanos universales o a nivel internacional.

Así, el grado de efectividad de los derechos humanos a nivel internacional, o de los derechos fundamentales, bajo el orden interno de cada país, reclama una mejor atención de las instituciones, en el sentido de dar más celo y más respeto a estos derechos. En consecuencia, si estos derechos no son respetados en su propio país, la comunidad internacional o los órganos legitimados pueden quejarse y formular la denuncia correspondiente ante los tribunales de protección de los derechos humanos.

De esta manera, la interpretación dada a los derechos humanos y fundamentales, se está consolidando en un cambio para la mejor protección de estos derechos. Por lo tanto, autorizada literatura recomienda la superación de la soberanía de los

\footnotetext{
${ }^{5}$ Piovesan, Flávia (2011). "Proteção dos Direitos Humanos: uma análise comparativa dos sistemas regionais europeu e interamericano”. En: Direitos Humanos, Democracia e Integração Jurídica. Rio de Janeiro: Lumen Juris, p. 626. Traducción del autor: "Refuerza la idea de que la protección de los derechos humanos no debe ser reducida al dominio reservado para el estado, porque revela un tema de legítima preocupación internacional".

${ }^{6}$ Bulygin (1987), p. 80.

7 Bulygin (1987), p. 84.
} 
Estados en la interpretación de las obligaciones internacionales relativas a los derechos humanos ${ }^{8}$. Es decir, una vez que se contrajo la obligación convencional de protección de los derechos humanos, el Estado parte no puede invocar su soberanía para no cumplir con el compromiso ante la comunidad internacional, así como no puede interpretar el Tratado respectivo de los derechos humanos teniendo en cuenta la primacía de concesiones recíprocas, porque el propósito buscado debe ser la protección de estos derechos fundamentales de los seres humanos?

De hecho, centrándose en los criterios para la interpretación de los tratados de derechos humanos, la Corte Interamericana de Derechos Humanos (CIDH), en respuesta a la consulta hecha por la República Argentina, por Brasil, Paraguay y Uruguay, en relación a los "Derechos y garantías de niñas y niños en el contexto de la migración y/o en necesidad de protección internacional', ha consignado la necesidad de "efectuar la interpretación más favorable para el efectivo goce y ejercicio de los derechos y libertades fundamentales, aplicando aquella norma que otorgue mayor protección al ser humano" 10 .

El énfasis en la protección de los derechos humanos en la óptica internacional se hace para destacar la mayor protección que brindan estos derechos, así como llamar la atención de la necesidad del cumplimiento de los tratados, convenios internacionales y las normas constitucionales, es decir, estándar interno y parte superior de cada país, para garantizar la legitimidad y la regularidad en el caso de la restricción de estos derechos en virtud de la cláusula de debido proceso.

En consecuencia, la correcta observancia del debido proceso, no sólo legal, sino convencional y constitucional, sobre la restricción de los derechos fundamentales de la persona humana, tiene un significado expresivo ante la supremacía de estos derechos, respecto de los cuales los Estados han comprometido respeto y adecuada tutela, ya que, en este caso, tiene validez el principio de la prevalencia de la dignidad humana ${ }^{11}$.

En particular en países como Brasil y otros latinoamericanos, que no hace mucho tiempo superaran los regímenes autoritarios, teniendo en cuenta las peculiaridades de la América Latina como "uma região marcada por um alto grau de exclusão e desigualdade social que se somam a democracias em fase de consolidação" 12 como

\footnotetext{
${ }^{8}$ Cançado Trindade, Antônio A. (2001). El Derecho Internacional de los Derechos Humanos en el Siglo XXI. Santiago: Editorial Jurídica de Chile, 2a Edición, pp. 22-23.

9 Cançado Trindade (2001), pp. 24-25.

${ }^{10}$ Corte Interamericana de Derechos Humanos. Opinión Consultiva OC-21/14, de 19 de agosto de 2014. Ponente Juez Humberto Antonio Sierra Porto. Disponible en: <www.corteidh.or.cr>. [Consulta: 15 enero 2015].

11 Piovesan (2011), p. 627.

12 Piovesan (2011), p. 633. Traducción del autor: "una región marcada por un alto grado de desigualdad social y exclusión que se suman a las democracias en fase de consolidación".
} 
enfatiza Piovesan, hay una necesidad de interpretar las disposiciones jurídicas con arreglo a los nuevos conceptos legales y democráticos.

Como ha deci|dido la Corte Interamericana de Derechos Humanos, también otros tribunales del poder judicial local deben interpretar las normas jurídicas para una "dinâmica e evolutiva interpretação, baseada na indivisibilidade e interdependência dos direitos humanos"13 y en conformidad con las normas jurídicas que estructuran los Estados democráticos.

De hecho, en la América Latina actual la mejor expresión de la indivisibilidad e interdependencia de los derechos humanos, sin duda, es el surgimiento de lo que se llama de "bloque de constitucionalidad". Se entiende como bloque de constitucionalidad, en este estudio, como un "mecanismo para el reconocimiento de rango constitucional a tratados de derechos humanos", es decir, cuando una norma constitucional "se ha establecido expresamente la jerarquía constitucional de ciertos instrumentos internacionales de derechos humanos" ${ }^{14}$, de tal manera que sirven como parámetro para el control de convencionalidad de las leyes aprobadas por el poder legislativo competente. Para el mejor análisis de bloque de constitucionalidad en América Latina, se hace referencia al valioso texto de Gôngora Mera.

Acerca de las normas formuladas por el Estado democrático de derecho y su impacto sobre la restricción de derechos fundamentales es lo que seguirá.

\section{LOS FUNDAMENTOS DEL ESTADO DEMOCRÁTICO DE DERECHO}

En este capítulo en particular, se debe considerar que el concepto sobre el Estado democrático de derecho no es muy pacífico. Sin embargo, es apropiada la comprensión de STRECK y MoraIs sobre el Estado democrático como un plus normativo en comparación con el Estado de derecho y con el Estado Social de derecho. Así que para los autores nominados, “(...) o Estado Democrático de Direito teria a caracterítica de ultrapassar não só a formulação do Estado Liberal de Direito, como também a do Estado Social de Direito -vinculado ao Welfare state neocaptalista- impondo à ordem jurídica e à atividade estatal um conteúdo utópico de transformador da realidade" 15 .

\footnotetext{
13 PiOvesan (2011), p. 655. Traducción del autor: "interpretación evolutiva y dinámica, basada en la indivisibilidad e interdependencia de los derechos humanos”.

${ }^{14}$ Góngora Mera, Manuel Eduardo (2014). "La Difusión del Bloque de Constitucionalidad en la Jurisprudencia Latinoamericana y su Potencial en la Construcción del Jus Constitutionale Commune Latinoamericano". En: Jus Constitutionale Commune en America Latina. Rasgos, Potencialidades y Desafios, México: UNAM, pp. 2-3.

15 Streck, Lenio Luiz y Morais, José Luiz Bolzan de (2008). Ciência Política e Teoria Geral do Estado. Porto Alegre: Livraria do Advogado, 6a Edição, p. 99. Traducción del autor: "(...) el Estado democrático tendría la función de superar no sólo la formulación del Estado liberal de derecho, así como el Estado Social de Derecho -relacionado con el Welfare state neocapitalista-imponiendo a las leyes y a la actividad del Estado un contenido utópico transformador de la realidad".
} 
Al abordar el tema sobre la historia de los derechos humanos, NowaK le da énfasis en los fundamentos filosóficos. De hecho, NowAK indica la doctrina racional de la ley natural que, a su vez, concibe la doctrina liberal fundada en los siguientes derechos: derecho a la vida, a la libertad, de la propiedad y seguridad, afirmada por John LOCKE y otros. En este modelo, como propugna NOWAK, ocurrió el "reconocimiento de los seres humanos como sujetos dotados de derechos contra la sociedad y ubicados en el centro del sistema social y jurídico" 16 . Según NowaK, esta primera versión del positivismo, originaria de la época de la ilustración en Europa, no sólo incluyó la primera generación de derechos humanos, así como el liberalismo político y la democracia.

En este particular, bajo la doctrina del Estado Social de derecho, se inició el desempeño positivo de los derechos colectivos y sociales. Al contrario, el Estado liberal abogó por la abstención de la intervención estatal en ciertos derechos de las personas. Cabe señalar que el Estado Social de derecho ha sobresalido en la intervención estatal, en la tutela y en la aplicación de los derechos fundamentales y los derechos sociales de las personas, superando al Estado liberal. Este pasaje se puede resumir, por lo señalado por Virgilio Afonso DA SiLVA, por la aplicación de la proporcionalidad ${ }^{17}$, precisamente la regla de prohibición de exceso (Übermaßverbot), para que el Estado inhiba la protección insuficiente o implemente la prohibición de una protección insuficiente (UNTERMASSVERBOT) de los derechos fundamentales, en particular, los sociales.

Específicamente con respecto a la democracia, NowAK señala que "El principio de la democracia es la personificación de la libertad política como se acuñó en la antigüedad, es decir, la libertad de los ciudadanos de participar de manera activa, más específicamente, de participar en el proceso de toma de decisiones políticas"18.

Entender el principio de la democracia, como lo propone NowAK, gana importancia cuando señala que la democracia no se limita a la libertad política de los ciudadanos, sino principalmente, el derecho a participar activamente en el proceso de toma de decisiones políticas, es decir, de las decisiones del Estado. No hay duda que la decisión que restringe un derecho fundamental, en la persecución penal, por el poder judicial, es una de las decisiones políticas.

De hecho, la nota fundamental de los Estados no democráticos o regímenes autoritarios es la voluntad y la unilateralidad de las decisiones estatales, incluso cuando se enfrentan a los derechos humanos y fundamentales. En este modelo de Estado es imposible la posibilidad de los interesados de participar en las decisiones

${ }^{16}$ NowAK, Manfred (2009). Introducción al Régimen Internacional de los Derechos Humanos. Buenos Aires: Editorial Universidad de Buenos Aires, 1a Edición, pp. 25-26.

17 Silva, Luís Virgílio Afonso da (2002). "O proporcional e o razoável”. Revista dos Tribunais, São Paulo, Año 91, No 798, p. 23.

${ }^{18}$ NOWAK (2009), p. 26. 
estatales, incluyendo, por ejemplo, en las decisiones adoptadas por el poder judicial en los procesos penales.

Diferentemente, en el Estado democrático de derecho, incluso cuando se trata de deliberar las decisiones acerca de los derechos fundamentales de la persona, como ocurre a menudo en las decisiones relativas al proceso penal, es evidente la necesidad de la participación de la persona en cuestión, ya sea por el requisito de ejercicio contradictorio, ya sea en el ejercicio de lectura amplia, pero esencialmente por medio de argumentos válidos para componer los fundamentos de la decisión judicial. Ejemplo típico de esta realidad es la posibilidad de que el juez, sin solicitud expresa y motivada de la fiscalía, condene a alguien por algún delito.

Es que, como se ha visto antes, dada la dimensión actual sobre el valor que otorga a los derechos fundamentales y humanos, ya sea en el orden jurídico internacional o en los sistemas jurídicos nacionales, es inconcebible que el poder judicial condene a alguien sin la petición de la fiscalía, es decir, sin solicitud explícita y con razones fácticas y jurídicas de condena por el fiscal o el ofendido.

En el Estado democrático, la participación de la persona en sus decisiones es más de lo necesario: es esencial, bajo pena de pérdida de legitimidad. En este sentido destaca la doctrina autorizada que la "democracia, por sua vez, implica participação" ${ }^{19}$. En esto sentido, si el proceso democrático pide la participación de los ciudadanos, esa participación puede encontrar amparo en la teoría del discur$\mathrm{so}^{20}$ que, por su vez, contempla y privilegia el consenso. Este es el paso siguiente.

\section{La TeOrÍa del CONSENSO de JÜRGEN Habermas}

En el supuesto de la acción comunicativa, como propugna HABERMAS, es posible superar el aislamiento de las decisiones estatales o arbitrarias, especialmente en el Estado democrático de derecho que, como se ve, pide participación de los involucrados o interesados.

El consenso prevé discurso y los participantes de este discurso pueden expresarse en busca de entendimiento. Según Habermas, los participantes deben manifestarse bajo ciertas condiciones o, precisamente, bajo las siguientes afirmaciones de validez: “-a pretensão de que o enunciado feito seja verdadeiro (ou de que os pressupostos existenciais de um teor proposicional mencionado sejam realmente cumpridos); -a pretensão de que a ação de fala seja correta com referência a um contexto normativo vigente (ou de que o contexto normativo

${ }^{19}$ Alberton, Genacéia da Silva (2004). "Ação Comunicativa e Jurisdição: uma contribuição habermasiana". Revista da Fundação Escola Superior do Ministério Público do Distrito Federal e Territórios, Año 12, Vol. 23, p. 87. Traducción del autor: "democracia, a su vez, implica participación".

${ }^{20}$ Habermas, Jürgen (2003). Direito e democracia: entre facticidade e validade. SiebeneICHLER, Flávio Beno (Trad.), Rio de Janeiro: Tempo Brasileiro, Vol. II, 2a Edição, pp. 19-25. 
que ela deve cumprir seja legítimo; e -a pretensão de que a intenção expressa do falante corresponda ao que ele pensa" 21 .

Estas afirmaciones, por cierto, estructuran la teoría de la acción comunicativa de HABERMAS, cuya profundización escapa a los límites y los objetivos del presente texto. Sin embargo, cabe destacar el concepto de la acción comunicativa "pressupõe a linguagem como médium de uma espécie de processos de entendimento ao longo dos quais os participantes, quando se referem a um mundo, manifestam de parte a parte pretensões de validade que podem ser aceitas ou contestadas"22. HABERMAS, más adelante, señala que la "linguagem é um médium de comunicação a serviço do entendimento" 23 .

En esta perspectiva, la teoría del consenso tiene afinidad razonable con los fundamentos del Estado democrático de derecho, teniendo en cuenta que en esto, como se ha visto antes, permite la participación de interesados en la formación de la decisión estatal. Se desvía de la decisión arbitraria o aislada, para acercarse a la decisión que toma en cuenta las manifestaciones de los interesados, especialmente sobre el cual esa decisión produce efectos jurídicos en cualquier derecho fundamental.

Dada la proximidad del tema, es decir, cuando se habla de argumentación y de la participación de interesados en la decisión judicial, no puede ignorar la tesis del caso especial (Sonderfallthese), propuesto por Robert AleXY ${ }^{24}$, que contrasta el modelo teórico de Habermas. Alexy considera en la argumentación jurídica el carácter autoritario e institucional. Para él, los argumentos que interpretan los derechos fundamentales de una constitución son la argumentación jurídica. El argumento jurídico, así como el argumento práctico general, tiene una pretensión de corrección aunque deba guardar coherencia con el conjunto del orden jurídico y con los precedentes. Además, para AleXY la argumentación jurídica debe entenderse como un caso especial del discurso práctico general, distintos del discurso moral propuesto por HABERMAS.

${ }^{21}$ Habermas, Jürgen (2012). Teoria do Agir Comunicativo: racionalidade da ação e racionalização social. Soethe, Paulo Astor (Trad.), São Paulo: Martins Fontes, Vol. 1, $1^{\text {a }}$ Edição, p. 192. Traducción del autor: "-intención de que la declaración es verdadera (o supuestos existenciales de un contenido proposicional mencionado realmente se cumplan); -la afirmación de que la acción es correcta referente a un contexto regulatorio existente (o que el contexto normativo que debe cumplir es legítimo); y -la afirmación de que la intención expresa del orador coincide con lo que piensa”.

${ }^{22}$ Habermas (2012), p. 191. Traducción del autor: "asume el lenguaje como un medio de algún tipo de procesos de comprensión sobre los participantes, cuando se refiere a un mundo, manifiestan en ambas afirmaciones lados de validez que pueden ser aceptados o impugnados".

${ }^{23}$ Habermas (2012), p. 194. Traducción del autor: "lenguaje es un médium de comunicación al servicio del entendimiento".

${ }^{24}$ Alexy, Robert (1999). "La tesis del caso especial". Isegoría Revista de Filosofía Moral y Politica. No 21, pp. 23-35. Disponible en: <http://isegoria.revistas.csic.es/index.php/isegoria/article/view/75/75>. 
Es posible comprender que la tesis del caso especial, como la propuesta por ALEXY, tiene un contenido, o mismo uno código, propio del razonamiento jurídico. Es decir, que la argumentación jurídica esté vinculada a las leyes, a los precedentes y al sistema de derecho elaborado por la dogmática jurídica. En este contexto, el distinguido jurista alemán sostiene que el argumento práctico general no debe cambiar su naturaleza cuando integrados en contextos jurídicos, de manera que el juez o el tribunal, con amparo en la ley democrática, pueda decir el derecho en el caso concreto de modo semejante a la regla do juria novit curia, en especial porque las partes normalmente sostienen intereses propios. Sin embargo, no se puede olvidar que el proceso judicial, en la persecución penal, las partes también conocen las leyes, el sistema del derecho de acuerdo con la dogmática jurídica y los precedentes. Además, la parte autora en la persecución penal es el Ministerio Público, órgano del Estado. También el representante del acusado, sea el abogado, sea el órgano de la Defensoría Pública, todos conocen el contenido del razonamiento jurídico.

De todas maneras, la discusión sobre la tesis del caso especial de AlEXY es interesante, pero su profundización se reserva para otra oportunidad. Por ahora, merece el registro de que los supuestos del consenso establecidos por HABERMAS deben estar de acuerdo con el derecho democrático vigente.

Además, el consenso no implica necesariamente la búsqueda de la verdad absoluta, sino más bien que los participantes pueden llegar a entendimiento posible sobre lo discutido en el proceso. Esta comprensión, por el consenso, se rompe, en cierta medida, con los procedimientos históricos que pretendían alcanzar las verdades absolutas.

Es en estos modelos procesales -especialmente los modelos jurisdiccionales de los Estados totalitarios-, donde las decisiones arbitrarias admiten el principio de la búsqueda de la verdad con pretensiones de verdad absoluta o verdad real. En estos casos, las personas en cuestión o cualquiera de las cuales podrían sufrir las consecuencias legales de la decisión (judicial), no participan en modo activo para la formación de la decisión del Estado o, si se permite su participación, sus argumentos no se consideran para conducir los motivos de esa decisión.

$\mathrm{Al}$ contrario, la teoría del consenso proporciona un espacio abierto para la participación del sujeto interesado o quien es alcanzado por el efecto jurídico de la decisión del Estado. Todavía, el discurso respaldado en las pretensiones de validez antes indicado, constituye, en cierto modo, uno de los pilares de la teoría de la argumentación de HABERMAS, cuya relevancia con el Estado democrático parece aceptable en la actualidad.

En particular, insta a informar la lección del profesor Martin AlDAO cuando aborda el tema de la obtención de la verdad en el marco de la teoría de la argumentación propuesta por HABERMAS, en el sentido siguiente: "No se trata de 'descubrir' una verdad a través del consenso, puesto que esta verdad existe sólo como 
presupuesto de los participantes del acto dialógico" ${ }^{25}$. En la secuencia, el eminente profesor procede así: "Esto es, si pretenden mantener algún tipo de racionalidad, deben suponer que es posible llegar a una verdad común, pero esto no significa que esta verdad exista efectivamente, sino más bien que su rechazo torna irracional cualquier tipo de argumentación dialógica y por lo tanto intersubjetivamente entendida" 26 .

En ese sentido, parece que la búsqueda de la comprensión, a través del discurso, no tiene como meta la búsqueda de la verdad, pero sólo toma como una suposición. En este caso, la verdad obtenida (no buscada) a través de la argumentación es la propia comprensión que resulta entre los involucrados, libres de cualquier coacción.

Destacando que el consenso se obtiene por el mejor argumento, HABERMAS establece cuatro supuestos que sirven como una regla entre los involucrados, así: "(a) publicidade e inclusão: ninguém que, à vista de uma exigência de validez controversa, possa trazer uma contribuição relevante, deve ser excluído; (b) direitos comunicativos iguais: a todos são dadas as mesmas chances de se expressar sobre as coisas; (c) exclusão de enganos e ilusões: os participantes devem pretender o que dizem; e (d) não-coação: a comunicação deve estar livre de restrições, que impedem que o melhor argumento venha à tona e determine a saída da discussão" 27 .

Sin embargo, cabe señalar que la posición de Martin $\operatorname{ALDAO}^{28}$ es en el sentido de que la teoría de la racionalidad argumentativa propuesta por HABERMAS podría tener un alto precio, que es en la deslegitimación de la mayoría de las instituciones de la democracia del Estado de derecho, llevando a la teoría de la acción comunicativa en condiciones casi anarquistas.

En cualquier caso, aunque no evaluado en concreto, los supuestos establecidos por HABERMAS garantizan, por lo tanto, lo que importa más, en la sustitución de la verdad por la aceptación racional del consenso.

Como se pretendía sostener, aunque la limitación y la brevedad de este texto, la contribución de HABERMAS puede ser válida en el contexto de la esfera procesal, donde se analiza y decide por la restricción de derecho fundamental de la persona, como será discutido más adelante.

\footnotetext{
${ }^{25}$ AldaO, Martin M. (2007). "Teoría de la Argumentación y Democracia”. Revista Electrónica del Instituto de Investigaciones "Ambrosio L. Gioja", Año 1, No 1, p. 14. Disponible en: <www.derecho.uba.ar/revistagioja/ articulo>. [Consulta: 14 enero 2015].

26 Ídem.

27 Habermas, Jürgen (2002). Agir Comunicativo e Razão Destrancendentalizada. AraGāo, Lúcia (Trad.), Camarinha Da Silva, Daniel (Rev.), Rio de Janeiro: Tempo Brasileiro, $1^{a}$ Ediçáo, p. 67. Traducción del autor: "(a) publicidad e inclusión: nadie que, a la vista de una exigencia de validez polémica, pueda traer una contribución relevante, debe ser excluido; (b) derechos comunicativos iguales: a todos son dadas las mismas oportunidades de expresarse sobre las cosas; (c) exclusión de errores y de ilusiones: los participantes deben pretender lo que dicen; y (d) no coacción: la comunicación debe estar libre de restricciones, que impiden que el mejor argumento arribe y determine la salida de la discusión".
}

${ }^{28}$ AldaO (2007), p. 15. 


\section{LA LEGITIMIDAD EN LA RESTRICCIÓN DE DERECHOS FUNDAMENTALES}

Como se ha visto antes, la posición actual de los derechos humanos a nivel internacional se está expandiendo en los niveles teóricos y en pleno reconocimiento por los tribunales internacionales en la protección de estos derechos. Además, la estructura actual de los derechos humanos, como los derechos fundamentales en las constituciones, tiene la misma dignidad y pide más respeto de los agentes del Estado.

Sin embargo, cabe hacer algunas consideraciones pertinentes a este punto. En primer lugar, sobre el concepto de legitimidad. La legitimidad, aquí considerada, se refiere al "grau de aceitação dos sistemas políticos e dos ordenamentos jurídicos" 29. En segundo lugar, en relación con el concepto de restricción. La restricción, indica la hipótesis de que el Estado puede, legítimamente, mitigar o reducir la plenitud del goce o el ejercicio de los derechos fundamentales, como ocurre en la restricción de la libertad como resultado de la condena penal, obedeciendo el debido proceso y la Constitución.

En el Estado democrático las decisiones estatales son tomadas o pueden ser tomadas por consenso, como propuesta de HABERMAS, rechazando las decisiones unilaterales o tomadas y realizadas bajo coacción. Esta misma comprensión puede y sirve para las decisiones del poder judicial.

Considerada la limitación del tema, no hay, en este texto, suficiente espacio para discutir la legitimidad del poder judicial, teniendo en cuenta el Estado democrático. Sin embargo, es cierto que las decisiones que emanan de ese poder deben ajustarse a los propósitos democráticos.

Como los tribunales internacionales de derechos humanos han establecido la flexibilización de la soberanía en la interpretación de las obligaciones convencionales de protección de los derechos humanos, indicados anteriormente, también los actos de soberanía interna, expresada por la jurisdicción del Estado, deben ceder a los fines del Estado democrático de derecho y asimilar la nota del consenso en varios procedimientos estatales, en particular en que se busca la restricción de un derecho fundamental, como ocurre en el proceso penal.

El modelo de la jurisdicción, especialmente la jurisdicción criminal, fundada sobre la confiabilidad de la decisión de un juez, es conveniente para el incipiente Estado de derecho que tuvo fuerte influencia de un "modelo liberal de jurisdição que se apresenta como atribuição do poder soberano do Estado de dizer o direito" ${ }^{30}$. Sin duda, este modelo no es compatible con el Estado democrático de derecho,

${ }^{29}$ FARIA, José Eduardo (1978). Poder e Legitimidade. São Paulo: Editora Perspectiva, 1a Edição, p. 58. Traducción del autor: "grado de aceptación de los sistemas políticos y de las órdenes jurídicas".

30 Alberton (2004), p. 90. Traducción del autor: "modelo liberal de jurisdicción que es la concesión del poder soberano del estado para decir el derecho". 
porque deja en evidencia un déficit de participación efectiva de los actores procesales, en especial de los que sufrirán los efectos de la decisión.

AlBERTON propone, por tanto, la "jurisdição-participação" o jurisdicciónparticipación en sustitución a la "jurisdição-soberania” o jurisdicción-soberanía. La nominada autora proclama así: "Na linha do modelo habermasiano do agir comunicativo, é viável a superação da jurisdição-soberania, ou seja, a jurisdição centrada apenas no poder soberano do Estado, numa relação de sujeito-objeto, decisão do Estado-Juiz que declarará quem será o ganhador ou o perdedor para irmos a busca de um modelo de jurisdição-participação" ${ }^{1}$.

Más adelante AlBERTON expone aún: “(...), é possível afirmar que a racionalização do direito que se realiza pelo exercício da jurisdição encontra sua legitimidade no discurso democrático que somente se efetiva com o atuar comunicativo de todos os sujeitos da relação processual em exame. Esse atuar, todavia, fora do Estado se apresenta com déficit democrático, pois oferece as mesmas limitaçóes da jurisdição interna, ou seja, a resistência à participação dos sujeitos, mantendo-se no modelo da jurisdição-soberania" ${ }^{32}$.

Finalmente, es posible concluir, según AlBerTon, que la jurisdicción debe seguir la estructura del Estado. En el Estado no democrático: jurisdicción-soberanía; en el Estado democrático: jurisdicción-participación. En este sentido, AlBERTON recomienda que: "A jurisdição é histórica, e, portanto, deve se adequar ao Estado em que ela se realiza. Assim, no Estado Democrático de Direito, quando passamos da jurisdição-soberania para uma jurisdição-participação, estamos apontando, com base na matriz habermasiana, para uma jurisdição que supera o modelo da jurisdição conflitual que busca pelo processo a solução de conflitos. Há, sim, pela participação dos sujeitos da relação, uma busca da pacificação pela coordenação do agir comunicativo, via entendimento, em prol do consenso. Os sujeitos são co-formadores do decidido"33.

\footnotetext{
${ }^{31}$ Alberton (2004), p. 90. Traducción del autor: “En consonancia con el modelo 'Habermasiano' de la acción comunicativa, es factible superar la jurisdicción-soberanía, es decir, la jurisdicción centrada solamente en el poder soberano del estado, en una relación sujeto-objeto, decisión del juez que declarará quién será el ganador o el perdedor para ir en búsqueda de un modelo de “jurisdicción-participación”".

32 Alberton (2004), pp. 90-91. Traducción del autor: “(...), es posible afirmar que la racionalización del derecho por el ejercicio de la jurisdicción encuentra su legitimidad en el discurso democrático que sólo entra en vigencia con el acto comunicativo de todos los sujetos de la relación procesal bajo revisión. Esta ley, sin embargo, fuera del estado tiene déficit democrático, porque ofrece las mismas limitaciones de la jurisdicción interna, es decir, la resistencia a la participación de los sujetos, permaneciendo en el modelo de la jurisdicción-soberanía”.

${ }^{33}$ Alberton (2004), p. 96. Traducción del autor: "La jurisdicción es histórica y por lo tanto debe adaptarse al estado en que se lleva a cabo. Así, en el estado democrático de derecho, cuando pasamos de jurisdicciónsoberanía a jurisdicción-participación, nos estamos apuntando, basado en la matriz habermasiana, a una jurisdicción que supera la jurisdicción conflictual que busca en el proceso la solución de conflictos. Hay, así, por la participación de los sujetos de la relación, una búsqueda de la paz mediante la coordinación de la acción comunicativa, mediante el entendimiento, en aras del consenso. Los sujetos son los formadores de lo decidido".
} 
Así, la primacía de los derechos fundamentales, en el Estado democrático de derecho, los derechos humanos, por lo tanto, exteriorizan su dignidad hasta tal punto que hace necesario repensar los supuestos que, en alguna medida, hacen posible su restricción. En este sentido, la teoría del consenso preconizada por HABERMAS se manifiesta como un instrumento eficaz para el Estado democrático, porque permite la participación de los interesados en la formación de la decisión estatal.

Principalmente en la jurisdicción criminal es necesario cambiar algunas prácticas al modelo democrático del Estado. Bajo esta estructura democrática, la decisión unilateral del juez gana el significado del totalitarismo, porque es sin la contribución de las partes y porque renuncia al consenso entre los sujetos procesales. Un ejemplo de decisión arbitraria puede ocurrir cuando, en la persecución penal, el juez limita el derecho de libertad de la persona, en la investigación o en el procedimiento, sin la indispensable solicitud motivada del órgano que promovió la acción penal (fiscal u ofendido), especialmente si esa legitimidad está asentada en la Constitución, como ocurre en Brasil y en Argentina.

Cabe destacar, que las instituciones argentinas están en mejor sintonía con la estructura democrática en la persecución penal, en particular cuando se defiende la necesidad de consenso entre los sujetos procesales. En este sentido, decidiendo los casos (fallos) "Tarifeño" y "Mostaccio" 34 , la Corte Suprema de Justicia de la Nación Argentina decidió la cuestión referente a la condena penal sin la petición de la fiscalía, teniendo como parámetro la Constitución. En estos casos, la Corte Suprema de Argentina decidió que en el caso de condena, sin solicitud del Ministerio Público, ocurre la violación de las garantías de defensa y el debido proceso. Estableció que el artículo 18 de la Constitución requiere la observancia de las formas sustanciales del juicio relativas a la acusación, defensa, prueba y sentencia dictada por los jueces naturales nacionales de Argentina. Además, en este caso, hubo condena sin petición de la fiscalía.

Según la doctrina de ANTONInI, en estos casos, la Corte Suprema ha expuesto argumentos más aproximados de un sistema acusatorio de enjuiciamiento. Esto significa que, en esas decisiones, la Corte Suprema de Justicia ha contribuido para una mejor distribución de las autoridades entre los miembros del sistema penal ${ }^{35}$. Estos juzgados de la Corte Suprema de Argentina, en buena medida, están de acuerdo con la teoría del consenso de HABERMAS, porque dan una conformación democrática en las decisiones judiciales que restringen el derecho fundamental.

En este punto, autorizada doctrina chilena defiende que en el sistema chileno la petición de absolución por el Ministerio Público no vincula al juez. Se entiende

\footnotetext{
${ }^{34}$ Antonini, Mónica A. (2005). "Formas Sustanciales del Proceso. Acusación y sentencia condenatoria”. En: Colección de Análisis Jurisprudencial - Elementos de Derecho Penal y Procesal Penal. Buenos Aires: La Ley, pp. 360-363.

35 Antonini (2005), p. 363.
} 
porque se analiza el principio de la congruencia en la perspectiva del escrito de acusación y no en el alegato de clausura ${ }^{36}$.

En la situación opuesta, en Brasil, la jurisprudencia de la Corte Superior de Justicia $^{37}$ viene a menudo respaldando la posición de que la condena penal es válida aun cuando el fiscal pide la absolución. Esta jurisdicción, que todavía se practica en Brasil, está próxima a la antes mencionada jurisdicción-soberanía, pero lejos de la jurisdicción-participación. Este cuadro desprestigia el necesario carácter fundamental de los derechos fundamentales, así como el aspecto democrático en la restricción de estos derechos en la persecución penal.

\section{ConClusión}

Los derechos humanos tendrán la naturaleza de derechos fundamentales en las condiciones previstas en el texto constitucional. Exactamente en este sentido es que retratan la doctrina y los tribunales internacionales de derechos humanos, que predican la derogación de la soberanía en la interpretación de los convenios que prescriben la protección de los derechos humanos.

Superar el gobierno autoritario de la ley, hacia el Estado democrático de derecho, es el objetivo actual, cuya perspectiva de sedimentación es reclamada por la comunidad internacional. La democracia puede entenderse como la participación de los interesados en las decisiones estatales, incluso las decisiones del poder judicial. Por lo tanto, la jurisdicción es reconocida como adecuada para el modelo del Estado respectivo; es decir, es histórica y adaptada a cada tipo de Estado. Así, en los Estados autoritarios, tendrá la "jurisdição-soberania” o jurisdicción-soberanía; en los Estados democráticos, tendrá la "jurisdição-participação" o jurisdicciónparticipación.

Así, la naturaleza fundamental de los derechos de las personas exige, en un Estado democrático de derecho, la participación de los interesados que sufrirán los efectos de la decisión estatal.

La legitimidad democrática en la restricción de los derechos de las personas, con la nota de derechos fundamentales, en particular cuando la decisión se procesa en la persecución penal, exige la participación de los sujetos en la preparación de la decisión. Exactamente en este contexto la teoría del consenso de HABERMAS está más en sintonía con los derechos humanos. De hecho, es porque rechaza las sentencias arbitrarias y autoritarias contra la persona como ser humano, exactamente por la autoridad (juez) en quien la Constitución impone el deber de proteger estos derechos.

${ }^{36}$ Horvitz Lennon, María Inés y López Masle, Julián (2004). Derecho Procesal Penal Chileno. Santiago: Editorial Jurídica de Chile, Tomo II, 1ª Edición, pp. 328-331.

37 Superior Tribunal de Justiça. Quinta Sala. Habeas Corpus No 197068-SP. Juzgado en 2013. Disponible en: <www.stj.jus.br>. [Consulta: 14 enero 2015]. 


\section{BibLIOGRAFÍA CITADA}

Alberton, Genacéia da Silva (2004). "Ação Comunicativa e Jurisdição: uma contribuição habermasiana”. Revista da Fundação Escola Superior do Ministério Público do Distrito Federal e Territórios, Año 12, Vol. 23, pp. 85-102.

AldaO, Martin M. (2007). “Teoría de la Argumentación y Democracia”. Revista Electrónica del Instituto de Investigaciones 'Ambrosio L. Gioja”, Año 1, No 1, pp. 8-16. Disponible en: <www.derecho.uba.ar/revistagioja/articulo>. [Consulta: 14 enero 2015].

AlEXY, Robert (1999). "La tesis del caso especial”. Isegoría Revista de Filosofía Moral y Politica. No 21, pp. 23-35. Disponible en: <http://isegoria.revistas.csic.es/ index.php/isegoria/article/view/75/75>.

Antonini, Mónica A. (2005). "Formas Sustanciales del Proceso. Acusación y sentencia condenatoria”. En: Colección de Análisis Jurisprudencial - Elementos de Derecho Penal y Procesal Penal. Buenos Aires: La Ley, pp. 360-363.

Bulygin, Eugenio (1987). "Sobre el Status Ontológico de los Derechos Humanos". En: Doxa. Cuadernos de Filosofía del Derecho, No 4, pp. 79-84.

CançAdo Trindade, Antônio A. (2001). El Derecho Internacional de los Derechos Humanos en el Siglo XXI. Santiago: Editorial Jurídica de Chile, 2a Edición, 553 pp.

Faria, José Eduardo (1978). Poder e Legitimidade. São Paulo: Editora Perspectiva,

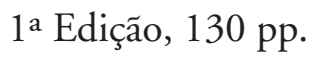

Góngora Mera, Manuel Eduardo (2014). "La Difusión del Bloque de Constitucionalidad en la Jurisprudencia Latinoamericana y su Potencial en la Construcción del Jus Constitutionale Commune Latinoamericano”. En: Jus Constitutionale Commune en America Latina. Rasgos, Potencialidades y Desafios, México: UNAM, pp. 1-30.

Habermas, Jürgen (2002). Agir Comunicativo e Razão Destrancendentalizada. Aragão, Lúcia (Trad.), Camarinha da Silva, Daniel (Rev.), Rio de Janeiro: Tempo Brasileiro, 1a Edição, $111 \mathrm{pp}$.

Habermas, Jürgen (2003). Direito e democracia: entre facticidade e validade. SIEBENEICHLER, Flávio Beno (Trad.), Rio de Janeiro: Tempo Brasileiro, Vol. II, 2a Edição, 352 pp.

Habermas, Jürgen (2012). Teoria do Agir Comunicativo: racionalidade da ação e racionalização social. SoEthe, Paulo Astor (Trad.), São Paulo: Martins Fontes, Vol. 1, 1a Edição, 704 pp.

Horvitz Lennon, María Inés y López Masle, Julián (2004). Derecho Procesal Penal Chileno. Santiago: Editorial Jurídica de Chile, Tomo II, 1a Edición, 659 pp.

NowaK, Manfred (2009). Introducción al Régimen Internacional de los Derechos Humanos. Buenos Aires: Editorial Universidad de Buenos Aires, $1^{\text {a }}$ Edición, 445 pp. 
DE DERECHO FUNDAMENTAL EN LA TEORÍA DEL CONSENSO DE JÜRGEN HABERMAS

Piovesan, Flávia (2011). "Proteção dos Direitos Humanos: uma análise comparativa dos sistemas regionais europeu e interamericano". En: Direitos Humanos, Democracia e Integração Jurídica. Rio de Janeiro: Lumen Juris, pp. 625-662.

SARLET, Ingo Wolfgang (2006). A Eficácia dos Direitos Fundamentais. Porto Alegre: Livraria do Advogado, 6a Edição, 461 pp.

SiecKmann, Jan (2012). “Derechos Humanos y Autonomía”. En: Internalización del Derecho Constitucional, Constitucionalización del Derecho Internacional, Buenos Aires: Editorial Eudeba/ Alexander von Humboldt, 1a Edición, pp. 631-644.

Silva, Luís Virgílio Afonso da (2002). "O proporcional e o razoável”. Revista dos Tribunais, São Paulo, Año 91, No 798, pp. 23-50.

STreck, Lenio Luiz y Morais, José Luiz Bolzan de (2008). Ciência Política e Teoria Geral do Estado. Porto Alegre: Livraria do Advogado, 6a Edição, 211 pp.

\section{JURISPRUDENCIA CITADA}

Superior Tribunal de Justiça. Quinta Turma. Habeas Corpus No 197068-SP. Juzgado en 2013. Disponible en: <www.stj.jus.br>. [Consulta: 14 enero 2015].

Corte Interamericana de Derechos Humanos. Opinión Consultiva OC-21/14, de 19 de agosto de 2014. Ponente Juez Humberto Antonio Sierra Porto. Disponible en: <www.corteidh.or.cr>. [Consulta: 15 enero 2015]. 